\title{
Bricqueville-sur-Mer - Extension de la mairie
}

\section{Daniel Hélye}

Édition électronique
URL : http://journals.openedition.org/adlfi/16699

ISSN : 2114-0502

Éditeur

Ministère de la culture

\section{Référence électronique}

Daniel Hélye, «Bricqueville-sur-Mer - Extension de la mairie », ADLFI. Archéologie de la France Informations [En ligne], Basse-Normandie, mis en ligne le 26 février 2016, consulté le 03 mai 2019. URL : http://journals.openedition.org/adlfi/16699

Ce document a été généré automatiquement le 3 mai 2019.

(c) Ministère de la Culture et de la Communication, CNRS 


\title{
Bricqueville-sur-Mer - Extension de la mairie
}

\author{
Daniel Hélye
}

Lien Atlas (MCC) :

http://atlas.patrimoines.culture.fr/atlas/trunk/index.php?

ap_theme=DOM_2.01.02\&ap_bbox=-1.567;48.903;-1.474;48.934

1 L'annexion en 1794 par la commune de Bricqueville-sur-Mer de la majorité du territoire de la petite paroisse de Sainte-Marguerite-sur-Mer, sa voisine, modifia sensiblement le tissu social local.

2 L'une des premières conséquences sera la fermeture au culte de l'église au grand bénéfice de sa voisine qui verra ainsi sa population augmenter de 30 à $40 \%$. Malgré des travaux onéreux pour l'agrandissement de la nef et la restauration des parties plus anciennes, l'église paroissiale de Bricqueville se révélera très rapidement trop petite et non appropriée à une population de plus de 2000 habitants. Dès 1874, l'abbé Germain, curé du lieu, envisage la construction d'une nouvelle église. Ce projet prend corps en 1876 . Pour des raisons financières, la durée des travaux sera plus longue que prévue ; ils ne seront totalement terminés qu'en 1889. Afin de réduire les coûts de construction et de transport des matériaux, décision fut prise de détruire les églises de Bricqueville-sur-Mer et de Sainte-Marguerite et d'employer les pierres à l'édification de la nouvelle. La vente d'une partie du cimetière à un particulier et les alignements routiers réduisirent sa surface d'environ $1 / 5^{\mathrm{e}}$. L'espace laissé vacant a permis à la municipalité de construire une petite mairie (1880). D'une superficie au sol de $70 \mathrm{~m}^{2}$ elle ne correspond plus aux besoins d'une commune tournée vers le modernisme. En 2008-2009, un projet d'agrandissement est mis à l'étude.

En 2011, le service régional de l'archéologie interviendra de manière préventive et effectuera quelques sondages. Les travaux de terrassement et de maçonnerie donnèrent lieu à un suivi archéologique pendant un an. Les relevés effectués permirent la localisation de certaines parties de l'église et de rétablir quelques vérités. 
4 Les fondations de la tour du clocher sont identifiées sur plus des trois quarts de leur emprise. Les murs gouttereaux nord et sud ont presque complètement disparu et ne subsistent que sous forme de lambeaux recoupés en de multiples endroits par des canalisations et des conduits de fluide. Nous avons cependant pu identifier trois étapes de construction où d'aménagement.

5 Aucun des vestiges repérés ne semble antérieur au $\mathrm{XI}^{\mathrm{e}} \mathrm{s}$., ils se situent à la jonction avec la reconstruction de la nef au $x_{1 X}{ }^{e}$ s. Les maçonneries imposantes du clocher $(2 \mathrm{~m}$ d'épaisseur) correspondent tout à fait aux tours massives $\mathrm{du}^{\mathrm{XIV}}{ }^{\mathrm{e}} \mathrm{s}$. destinées aussi bien à recevoir les cloches qu'à servir de refuge en cas de conflit. L'église fut l'objet de travaux importants tout particulièrement au $\mathrm{XvII}^{\mathrm{e}} \mathrm{s}$. avec la pose d'un pavage dans le chœur de l'église. Nous ignorons si la nef et le clocher étaient aussi dallés, nous n'avons rien retrouvé qui puisse étayer cette éventualité. Un sol en terre battue paraît s'imposer de lui-même.

6 Les constructions modernes, mairie et salle polyvalente, donnèrent lieu à des périodes différentes au creusement de plusieurs fosses communes. Deux sont localisées. La première à l'ouest de la mairie, contemporaine de la construction de celle-ci, et la seconde entre la mairie et la salle polyvalente, qui date des années 1965-70, époque à laquelle elle fut bâtie, détruisant ainsi tous les niveaux anciens.

\section{INDEX}

Mots-clés : bâti, fondation, mur gouttereau

Index géographique : Basse-Normandie, Manche (50), Bricqueville-sur-Mer

Index chronologique : Moyen Âge, Temps Modernes

\section{AUTEUR}

DANIEL HÉLYE

BEN 